\title{
Chest dual energy CT to assess the effects of steroids on lung function in severe COVID-19 patients
}

Gaetano Perchiazzi

Uppsala University

Aleksandra Larina

Uppsala University

Tomas Hansen

Uppsala University

Robert Frithiof

Uppsala University

Michael Hultström

Uppsala University

Miklos Lipcsey

Uppsala University

Mariangela Pellegrini ( $\nabla$ mariangela.pellegrini@surgsci.uu.se)

Uppsala University

\section{Research Article}

Keywords: COVID-19, Dual Energy CT, Steroids, Hypoxic Pulmonary Vasoconstriction

Posted Date: March 7th, 2022

DOI: https://doi.org/10.21203/rs.3.rs-1405361/v1

License: (9) (i) This work is licensed under a Creative Commons Attribution 4.0 International License.

Read Full License 


\section{Abstract}

Background. Steroids have been shown to reduce inflammation, hypoxic pulmonary vasoconstriction (HPV) and lung oedema. Based on evidences from clinical trials, steroids are widely used in severe COVID-19. However, the effect on lung aeration and perfusion in this group of patients are unexplored.

Objective. Profiting by dual energy computed tomography (DECT), we investigated whether steroids affect HPV in severe COVID-19 and whether they reduce lung oedema and improve gas distribution.

Methods. Severe COVID-19 patients included in a single-center prospective observational study at the intensive care unit at Uppsala University Hospital who had undergone DECT were enrolled in the current study. Patients' cohort was divided in two groups depending on the administration of steroids. From each patient's DECT, 20 inflation maps and 20 perfusion maps, evenly distributed along the cranial-caudal axis, were analyzed. To estimate HPV, perfusion distribution was analyzed in both the whole lung and the hypoinflated areas. Total lung weight, index of lung oedema, was estimated.

Results. Sixty patients were analyzed, whereof 43 received steroids. Patients exposed to steroids showed a better (non-perfused area 10\% vs $15 \%, p<0.01$ ) and more homogeneous (kurtosis: 2.51 vs $1.85, p<$ 0.01 ) perfusion of hypoinflated areas, indicating reduced HPV. Moreover, they showed a significantly lower lung weight (853gr vs $1005 \mathrm{gr}, \mathrm{p}=0.01)$.

Conclusions. The use of steroids was associated with impaired HPV and reduced lung oedema in severe COVID-19. This is consistent with previous findings in other diseases. Moreover, reduced lung weight and a more homogeneous distribution of gas within the lung were shown in patients treated with steroids.

Trial registration: Clinical Trials ID: NCT04316884, Registered March 13, 2020

\section{Background}

The spread of the COVID-19, caused by the beta coronavirus SARS-CoV-2, lead to the declaration of a pandemic in March 2020 [1]. Since then, an "unprecedented flood of research on the coronavirus" [2] brought to the elucidation of many molecular mechanisms subtending the disease [3-5]. However, although the prompt recognition of the consequences of SARS-CoV-2 on different organs and functions [6], the pathophysiological mechanisms affecting the respiratory function still remain to be thoroughly understood. This difficulty derives from the fact that the primary function of the respiratory system, i.e., the gas-exchange, is based on the interplay of two different sub-systems [7], alveolar ventilation and pulmonary capillary perfusion that deal with different physiological mechanisms and are associated to different structural features.

Numerous drugs have been tested as anti-SARS-CoV-2 agents [8]. Among them, steroids (i.e., dexamethasone $6 \mathrm{mg}$ for 10 days) have been demonstrated to improve survival $[9,10]$ and are therefore widely used in severe COVID-19. Despite their effectiveness and well-known pleiotropic effects [11], the 
pharmacodynamics of steroids on COVID-19 lungs have not been widely reported yet. Based on previous literature, a steroid-induced dysregulation of hypoxic pulmonary vasoconstriction (HPV) $[12,13]$ as well as a reduction of lung oedema [14] can be hypothesized also in COVID-19 patients.

Already at an early stage of the pandemic, evidence of lung perfusion abnormalities was reported based on dual energy computed tomography (DECT) [15]. Contrast-enhanced DECT is a powerful lung imaging method based on two concurrent $x$-ray energy spectra. Taking advantage of the different attenuation profiles of different substances, including iodine contrast, DECT can simultaneously characterize regional distribution of gas and of blood in the lung parenchyma $[16,17]$.

The main objective of this study was to investigate the effects of steroids on regional distribution of lung inflation and perfusion as indices of shunting affecting oxygenation in critically ill patients with severe COVID-19 using data from contrast-enhanced DECT.

The study had three main aims. Firstly, to examine the possibility of visualize pharmacodynamical mechanisms of drugs on lung parenchyma using DECT. Secondly, to investigate the association between steroids and HPV in COVID-19 lungs and therefore examine the influence of steroids on ventilation/perfusion matching. Thirdly, explore the association between steroids therapy and magnitude of lung oedema and consequently the effects on regional distribution of gas volume.

\section{Methods}

\section{Study population}

We analyzed clinically indicated DECT performed on patients included in a prospective observational single center study of critically ill COVID-19 patients admitted to the intensive care unit (ICU) at Uppsala University Hospital in Sweden between April 7th, 2020 and January 18th, 2021. The study was approved by the National Ethical Review Agency (EPM; No. 2020 - 01623) and performed according to the Declaration of Helsinki and its subsequent revisions. Patients older than 18 years with positive PCR test for SARS-CoV2 on nasal swab specimen and available chest DECT performed during the intensive care stay were analyzed. The scans were acquired on clinical indication in static lung conditions, covering the whole lung parenchyma in supine position (see Fig. 1). Comprehensive clinical data were collected at ICU admission and the day of DECT. Patients were analyzed in two groups consisting of those who were not treated with steroids (labelled as "No-Steroids") and those admitted after the early report of the RECOVERY dexamethasone trial in June $2020[10,18]$ who were treated with steroids (labelled as "Steroids").

\section{DECT image analysis}

For each DECT, two different series of images were selected: the gas-distribution (inflation) map and the corresponding blood-distribution (perfusion) map (see Fig. 1). Twenty images evenly spaced along the cranial-caudal axis and located between the apex and the diaphragmatic dome were analyzed (see 
Fig. 1). As regard to the inflation maps, the Hounsfield units (HU) range between $-1,000$ (gas) and +100 (non-aerated lung) was considered, as done in previous studies (see Fig. 2). Four lung compartments were then defined [19]: hyperinflated $(-1,000$ to $-800 \mathrm{HU})$, normoinflated $(-800$ to $-500 \mathrm{HU})$, poorly inflated $(-500$ to $-100 \mathrm{HU})$ and non-inflated $(-100$ to $+100 \mathrm{HU})$ lung. As regard to the perfusion maps, we studied the range between -100 and $+150 \mathrm{HU}$ (see Fig. 2). Based on previous studies [20-22], zero $\mathrm{HU}$ was set as limit between non-perfused $(\mathrm{HU} \leq 0)$ and perfused lung compartment $(H U>0)$. Each compartment was separately computed and expressed as $\mathrm{cm}^{2}$ and as percentage of the total lung area in each map. The kurtosis of the bell-shaped curves characterizing the HU distribution in perfusion maps was calculated [22] (see Fig. 3A). A reduced kurtosis corresponded to a decreased homogeneity of perfusion. The latter was interpreted as index of the efficiency of the HPV: a lower homogeneity of perfusion [23] corresponding to a higher HPV. To further assess HPV, where a reduced perfusion is expected in the hypoinflated lung, perfusion was separately assessed for the whole lung and for the hypoinflated areas, the latter characterized by poorly inflated and not inflated lung regions (i.e., between 500 and $+100 \mathrm{HU}$ ) (see Fig. 3).

\section{Lung weight analysis}

Total lung volume $(\mathrm{ml})$, total gas volume $(\mathrm{ml})$ and lung weight $(\mathrm{g})$ were computed [24-27]. The analysis was performed for the whole population as well as separately for the No-Steroids and the Steroids group.

\section{Statistical analysis}

Continuous variables were reported as medians and interquartile range (25th -75 th percentiles). The Wilcoxon signed rank test $(\alpha=0.05)$ was chosen as nonparametric test for paired observations. The Wilcoxon rank sum test $(\alpha=0.05)$ was used as nonparametric test in case of independent observations. Fisher's exact test $(\alpha=0.05)$ was used to test statistically significant differences in case of categorical variables. More details about Materials and methods are reported as online data supplement.

\section{Results}

\section{Study population}

Sixty patients affected by severe COVID-19 and in need of intensive care were analyzed in the study (see Table 1). The median age was of 63 years (IQR 57-68) and $20 \%$ were women. At ICU admission the ratio of partial pressure of arterial oxygen to inspired oxygen fraction at the day of the DECT was $117 \mathrm{mmHg}$ (96-140) and the SAPS3 was 50 (46-59). During their ICU stay before DECT, $41 \%$ of patients were intubated and $22 \%$ experienced an acute thrombotic event. In this selected population the 30-day mortality was $29 \%$. Forty-three out of sixty patients (72\%) received steroids for the treatment of COVID-19 associate pneumonia (Dexamethasone $6 \mathrm{mg}$ for 10 days) $[9,10]$. In order to compare the severity of the disease in N-Steroid and Steroid patients we analyzed a wide selection of clinical and biochemical markers (see Table 2). The Steroids-group showed a lower incidence of thrombotic events: $14 \%$ compared to $41 \%$ ( $\mathrm{p}=0.03$ ), as well as a lower inflammation (e.g., IL6 equal to $226 \mathrm{pg} / \mathrm{ml}$ in the No-Steroids group vs 
$86 \mathrm{pg} / \mathrm{ml}$ in the Steroids group, $\mathrm{p}=0.01$ ). The antithrombotic treatment (the dose of Deltaparin $\mathrm{per} \mathrm{kg}$ ) as well as the value of factor $\mathrm{Xa}(\mathrm{p}=0.11)$ did not differ between the two groups.

\section{DECT image analysis}

The $\mathrm{HU}$ analysis describing the gas distribution in the whole lung parenchyma showed two peaks corresponding to the hyperinflated and to the non-inflated HU compartments (see Figure 3 and Table E1). The analysis of perfusion distribution showed $12 \%$ of non-perfused areas in the whole lung and $11 \%$ in the hypoinflated lung $(p=0.06)$. The kurtosis characterizing the $\mathrm{HU}$ distribution in perfusion maps showed a significantly lower value (lower homogeneity) in the hypoinflated lung compared to the whole lung parenchyma. This was true for the whole population (2.88 vs 2.33 ) as well as for the two analyzed subgroups: No-Steroids (2.41 vs 1.85) and Steroids group (3.09 vs 2.51) (see Figures 3-4 and Tables E1E2). Patients treated with steroids showed a smaller amount of non-inflated lung, compared to patients not exposed to steroids ( $7 \%$ vs $10 \%, p=0.01$ ). However, steroids did not affect the extension of hyperinflated lung $(11 \%$ vs $12 \%, p=0.11)$. Hypoinflated areas of the lung showed a significantly lower perfusion in the Steroids group compared to the No-Steroids group (10\% vs $15 \%, p<0.01)$. Exposure to steroids increased the kurtosis (homogeneity) of the distribution of blood within the lung parenchyma, regardless of the degree of inflation (2.41 vs 3.09, $p<0.01$ for the whole lung and, 1.85 vs $2.51, p<0.01$ for the hypoinflated lung). The high kurtosis found in the Steroids groups stands for a reduced HPV (see Figures 4 and Figure E2).

\section{Lung weight analysis}

The analysis of total lung volume, gas volume and lung weight are reported in Table 3-5. The whole population showed a median lung weight of $911 \mathrm{gr}(\mathrm{IQR}=706-1125)$ and a median total gas volume of $1275 \mathrm{ml}$ (753-1728). The total lung extension was $2175 \mathrm{ml}$ (1477-2799) of which $42 \%$ was hyperinflated and $14 \%$ was not-inflated. By dividing the patients based on their exposure to steroids, significant differences were observed of lung extensions and lung weight. The group of patients exposed to steroids showed a significantly lower lung weight (853 g vs $1005 \mathrm{~g}, \mathrm{p}=0.01)$ as well as a significantly lower amount of non-inflated lung parenchyma ( $7 \%$ vs $10 \%, p=0.02)$ compared to patients not exposed to steroids. The total gas volume inside the lung was not affected by steroids ( $1275 \mathrm{vs} 1275 \mathrm{ml}, \mathrm{p}=0.71$ ).

\section{Discussion}

To date, despite established evidences of a reduced mortality in severe COVID-19 patients treated with steroids compared to a control population $[9,10]$ no studies reported the pathophysiological mechanisms and the effects of steroids on the lungs in this patients' population. In the current study, for the first time, we introduced the use of dual energy computed tomography to quantify the effects of steroids on lung pathophysiology in patients affected by severe COVID-19 and in need of intensive care. The main findings of the current study can be summarized as following: 1) steroids counteracted hypoxic pulmonary vasoconstriction; 2 ) steroids reduced lung oedema and consequently improve regional gas distribution in this cohort of COVID-19 patients with severe respiratory failure. 
In clinical contexts different from COVID-19, steroids have already been described to counteract hypoxic pulmonary vasoconstriction $[12,13]$ and, at the same time, for reducing oedema [14]. The current study is the first investigating the effects of steroids on lungs by using chest contrast-enhanced DECT and confirming these findings in critically ill patients affected by severe COVID-19. The known mechanisms of action of steroids on lungs pathophysiology are multifold. Steroid therapy is known for improving pulmonary function in preterm newborns by augmenting nitric oxide-mediated vessels relaxation as well as by stimulating surfactant production [28]. In the context of high-altitude pulmonary oedema (HAPE), dexamethasone has been proven to be effective in counteracting the generalized and powerful HPV of patients prone to acute mountain sickness $[12,13]$.

Steroids prevent capillary leak, stimulating alveolar sodium and water reabsorption [14] and enhance nitric oxide availability in the lung parenchyma [29]. There is a still ongoing debate about the possible benefits of their anti-inflammatory and antifibrotic properties on patients with acute respiratory distress syndrome $[30,31]$.

Interestingly, in the current study, the Steroids and the No-Steroids groups were similar to each other in all respects except for the indexes of inflammation and the onset of thromboembolic events during their ICU stay (see Table 2). Patients treated with steroids showed significantly lower inflammatory markers and, at the same time, a lower occurrence of thromboembolic events ( $19 \%$ vs $47 \%, p=0.04)$. The dose of antithrombotic drugs as well as the levels of factor Xa and D-dimers could not justify such differences. Although concomitant causes potentially influencing the prothrombotic state of these patients cannot be ruled out, the immunomodulatory effects and antithrombotic properties of steroids [32] can be a possible explanation for these differences [33]. Although not reaching statistical significance, patients treated with steroids showed an improved oxygenation $\left(\mathrm{PaO}_{2} / \mathrm{F}_{1} \mathrm{O}_{2}: 134\right.$ vs $125, \mathrm{p}=0.43$ ) and static compliance (43 vs $38, p=0.49$ ) as well as less days of mechanical ventilation and days of ICU stay. The sample was underpowered to investigate a difference in mortality between the two groups.

\section{Effects of steroids on hypoxic pulmonary vasoconstriction}

$\mathrm{HPV}$ is a homeostatic mechanism, peculiar of the pulmonary vasculature. Intrapulmonary arteries constrict in response to alveolar hypoxemia, diverting blood from injured lung regions towards better ventilated lung regions. Thereby, HPV optimizes the ventilation/perfusion match and improves oxygen delivery $[34,35]$. A dysregulated HPV has been hypothesized in COVID-19 patients [36, 37]. The current study was not designed to grade the HPV derangement induced by COVID-19. However, based on the collected data, we demonstrated that patients affected by severe COVID-19 and treated with steroids showed an additional reduction of HPV mechanisms (see Fig. 4-5 and Table E2). The evidence of a damped HPV might not be considered in line with the known beneficial effects of steroids observed in severe COVID-19 patients [9,38]. However, other concomitant beneficial mechanisms induced by steroids as anti-inflammatory and immunomodulatory effects, as well as the reduction of lung oedema, can be assumed to compensate for the negative effects deriving from a lost/worsened HPV and a ventilation/perfusion mismatch. Concurrently, also other mechanisms, as superinfections by Gram 
negative bacteria, potentially less hindered in patients treated with steroids, could possibly attenuate HPV [39].

\section{Effects of steroids on lung oedema}

At the pulmonary level, steroids prevent inflammatory capillary leak and oedema, stimulating alveolar sodium and water reabsorption [14]. We demonstrated a reduced lung weight as well as lower extension of non-inflated lung in patients treated with steroids compared to control (see Table 3-5).

Although not affecting global gas volume (see Table 3-5), steroids improved the homogeneity of gas distribution within the lung parenchyma (see Fig. 4 and Table E2). The exposure to steroids reduced the non-inflated, atelectatic lung compartment. These findings can also be interpreted as a consequence of a reduced lung oedema and inflammation following treatment with steroids.

Alongside emerging understanding of the pulmonary vascular involvement in COVID-19 patients, the key mechanism of the most immediately dangerous consequence of COVID-19 (hypoxemia) has been ascribed to the concurrent disruption of the tri-compartmental model of lung oxygenation [40]. Consequently, research has progressively focused upon the ventilation/perfusion mismatch. Mauri et al. [41] in a small cohort of COVID-19 patients, studied using electrical impedance tomography, reported that ventilation/perfusion mismatch was elevated and mainly due to nonperfused but ventilated units. Later, using a computational model, Busana et al. [42] attributed hypoxemia of COVID-19 to a marked hyperperfusion of poorly ventilated lung regions.

Given its availability in clinical practice chest contrast-enhanced DECT is emerging as promising tool for studying lung physiology $[43,44]$. The strength of DECT is that it simultaneously provides information about both gas and blood distribution and, consequently, has great potential in describing ventilation/perfusion dysregulation in COVID-19 [45]. Recently, Ball et al. [20] performed the first quantitative study regarding the distribution of gas volume and blood in the lungs of patients affected by COVID-19 by using DECT, reporting several deviations from the physiology, among which perfusion of non-aerated tissue mass.

This is the first study based on chest DECT investigating the functional effects of steroids on lungs in patients affected by severe COVID-19. Compared to previous literature, the current study took a step forward, not only investigating the regional distribution of lung inflation and perfusion in COVID-19, but also characterizing the effects that steroids have on them. We investigated pathophysiological mechanisms that contribute to the ventilation/perfusion mismatch characterizing COVID-19 lungs.

Limitations of the study can be listed as follow. Being an observational study, the analysis is based on DECT performed on the basis of a clinical indication and this might imply a selection bias. However, all COVID-19 patients admitted to our ICU with very few exceptions underwent either computed tomography with contrast or DECT. The fact that steroids have been introduced at a specific time of the pandemic might introduce a chronology bias into the study. As matter of fact, the SARS-CoV2 pandemic during its 
course has been characterized by a continuous change of treatment strategies and clinical routines that affect the generalizability of many studies on COVID-19. Given the demonstrated positive effects of steroids and their routinely use in severe COVID-19 patients [18], a prospective study comparing patients exposed or not-exposed to steroids, would have entailed unsolvable ethical issues. Steroids have pleiotropic effects [11] and the current study investigated only some possible consequences of pharmacodynamics mechanisms characterizing steroids. Chest DECT provides static information about gas volume at one predefined moment. Inflation maps are widely used in literature as surrogate of ventilation maps [19]. The same applies to DECT perfusion maps: although DECT generate images of blood distribution at one time point, several studies have demonstrated that DECT imaging can be used to assess lung perfusion [46].

\section{Conclusions}

Chest DECT can provide unique functional information and visualize the effects of pharmacodynamical mechanisms of drugs on lung parenchyma. Taking advantage of chest DECT, we demonstrated the association between the use of steroids and hypoxic pulmonary vasoconstriction in severe COVID-19 patients in need of intensive care. Steroids can influence ventilation/perfusion mismatch. Moreover, treatment with steroids is associated with a reduced lung oedema and consequently can improve regional distribution of gas volume within the lungs of severe COVID-19 patients.

\section{Abbreviations}

BMI

body mass index

COVID-19

coronavirus disease 2019

CT

computed tomography

DECT

dual energy computed tomography

$\mathrm{F}_{1} \mathrm{O}_{2}$

inspiratory fraction of oxygen

HAPE

high-altitude pulmonary oedema

HU

Hounsfield units

HPV

hypoxic pulmonary vasoconstriction

ICU

intensive care unit 
IL-6

interleukin 6

IQR

interquartile range

$\mathrm{PCO}_{2}$

partial pressure of arterial carbon dioxide

$\mathrm{PaO}_{2}$

partial pressure of arterial oxygen

$\mathrm{PaO}_{2} / \mathrm{F}_{1} \mathrm{O}_{2}$

ratio of arterial oxygen partial pressure to fractional inspired oxygen

PCR

polymerase chain reaction

SAPS 3

simplified acute physiology score 3

$\mathrm{SpO}_{2}$

peripheral oxygen saturation

\section{Declarations}

\section{Ethics approval and consent to participate.}

The presented data are part of a study approved by the National Ethical Review Agency (EPM; No. 2020--01623). The Declaration of Helsinki and its subsequent revisions were followed. Informed consent was obtained from the patient or from next of kin if the patient was unable to give consent.

\section{Consent for publication.}

Not applicable

\section{Availability of data and materials.}

Data is available from the corresponding author on reasonable request after appropriate ethical and data safety requirements are met (https://doi.org/10.17044/scilifelab.14229410).

\section{Competing interests.}

The authors declare that they have no competing interests.

Funding. The study was funded by the SciLifeLab/KAW national COVID-19 research program project grant to MH (KAW 2020.0182 and KAW 2020.0241); the Swedish Research Council grant to RF (201402569 and 2014-07606) and to GP (2018-02438); the Swedish Heart and Lung foundation to GP (20200877 and 20200825) and MH (2021-0089, 2019-0639, 2019-0637); the Swedish Society for Medical Research to MP (463402221); the Swedish Society of Medicine to MP (SLS-959793) and the Alvar 
Gullstrand research grant to GP (ALF-938050). Funding bodies had no role in the design of the study, collection and interpretation of data or in the writing of the manuscript.

\section{Authors' contributions}

Robert Fritihof, Miklos Lipcsey and Michael Hultström conceived the study on COVID-19 and inflammatory markers. Mariangela Pellegrini and Gaetano Perchiazzi conceived the study on DECT and designed the method of analysis. All the authors analyzed and interpreted the data of the study. Mariangela Pellegrini and Gaetano Perchiazzi drafted the manuscript and all the other authors revised it critically for important intellectual content. All the authors approved the final version of the manuscript and agreed to be accountable for all aspects of the work.

\section{Acknowledgements}

The authors thank the study nurses Elin Söderberg and Joanna Wessbergh, the radiology assistant Monica Segelsjö and the biobank research assistants Amanda Svensson, Labolina Spång, Philip Karlsson and Erik Danielsson for their expert help with compiling study data and organising sample analysis.

\section{References}

1. World Health Organization(WHO). Timeline of WHO's response to COVID-19 [Internet]. WHO webpage. 2020 [cited 2020 Jul 7]. Available from: https://www.who.int/news-room/detail/29-06-2020covidtimeline

2. Else H. How a torrent of COVID science changed research publishing - in seven charts. Nature. 2020;588:553-553.

3. Santacroce L, Charitos IA, Carretta DM, De Nitto E, Lovero R. The human coronaviruses (HCoVs) and the molecular mechanisms of SARS-CoV-2 infection. Journal of Molecular Medicine. Journal of Molecular Medicine; 2021;99:93-106.

4. Libby P, Lüscher T. COVID-19 is, in the end, an endothelial disease. European Heart Journal. 2020;41:3038-44.

5. Osuchowski MF, Winkler MS, Skirecki T, Cajander S, Shankar-Hari M, Lachmann G, et al. The COVID19 puzzle: deciphering pathophysiology and phenotypes of a new disease entity. The Lancet Respiratory Medicine. 2021;9:622-42.

6. Gavriatopoulou M, Korompoki E, Fotiou D, Ntanasis-Stathopoulos I, Psaltopoulou T, Kastritis E, et al. Organ-specific manifestations of COVID-19 infection. Clinical and Experimental Medicine. Springer International Publishing; 2020;20:493-506.

7. Glenny RW, Robertson HT. Determinants of pulmonary blood flow distribution. Comprehensive Physiology. 2011;1:39-59. 
8. Pluskota-Karwatka D, Hoffmann M, Barciszewski J. Reducing SARS-CoV-2 pathological protein activity with small molecules. Journal of Pharmaceutical Analysis. Elsevier Ltd; 2021;11:383-97.

9. RECOVERY Collaborative Group, Horby P, Lim WS, Emberson JR, Mafham M, Bell JL, et al. Dexamethasone in Hospitalized Patients with Covid-19. The New England journal of medicine. 2021;384:693-704.

10. WHO Rapid Evidence Appraisal for COVID-19 Therapies (REACT) Working Group, Sterne JAC, Murthy S, Diaz J V., Slutsky AS, Villar J, et al. Association Between Administration of Systemic Corticosteroids and Mortality Among Critically III Patients With COVID-19: A Meta-analysis. JAMA. 2020;324:1330-41.

11. Rhen T, Cidlowski JA. Antiinflammatory Action of Glucocorticoids - New Mechanisms for Old Drugs. New England Journal of Medicine. 2005;353:1711-23.

12. Maggiorini M. High altitude-induced pulmonary oedema. Cardiovascular Research. 2006;72:41-50.

13. Bliss A, Mahajan S, Boehm KM. Systematic Review of the Effects of Phosphodiesterase- 5 Inhibitors and Dexamethasone on High Altitude Pulmonary Edema (HAPE). Spartan Medical Research Journal. 2019;3:1-6.

14. Matthay MA, Clerici C, Saumon G. Active fluid clearance from the distal air spaces of the lung. Journal of applied physiology (Bethesda, Md: 1985). 2002;93:1533-41.

15. Lang M, Som A, Mendoza DP, Flores EJ, Reid N, Carey D, et al. Hypoxaemia related to COVID-19: vascular and perfusion abnormalities on dual-energy CT. The Lancet Infectious Diseases. Elsevier Ltd; 2020;20:1365-6.

16. Lu GM, Zhao Y, Zhang LJ, Schoepf UJ. Dual-energy CT of the lung. AJR American journal of roentgenology. 2012;199:S40-53.

17. Godoy MCB, Naidich DP, Marchiori E, Assadourian B, Leidecker C, Schmidt B, et al. Basic principles and postprocessing techniques of dual-energy $\mathrm{CT}$ illustrated by selected congenital abnormalities of the thorax. Journal of Thoracic Imaging. 2009;24:152-9.

18. Dexamethasone in Hospitalized Patients with Covid-19. New England Journal of Medicine [Internet]. 2021;384:693-704. Available from: http://www.nejm.org/doi/10.1056/NEJMoa2021436

19. Gattinoni L, Caironi P, Pelosi P, Goodman LR. What has computed tomography taught us about the acute respiratory distress syndrome? Am J Respir Crit Care Med. 2001;164:1701-11.

20. Ball L, Robba C, Herrmann J, Gerard SE, Xin Y, Mandelli M, et al. Lung distribution of gas and blood volume in critically ill COVID-19 patients: a quantitative dual-energy computed tomography study. Critical care (London, England) [Internet]. Crit Care; 2021 [cited 2022 Jan 18];25. Available from: https://pubmed.ncbi.nlm.nih.gov/34154635/

21. Mellemgaard K. The alveolar-arterial oxygen difference: its size and components in normal man. Acta physiologica Scandinavica [Internet]. Acta Physiol Scand; 1966 [cited 2022 Jan 18];67:10-20. Available from: https://pubmed.ncbi.nlm.nih.gov/5963295/

22. Uhrig M, Simons D, Ganten MK, Hassel JC, Schlemmer HP. Histogram analysis of iodine maps from dual energy computed tomography for monitoring targeted therapy of melanoma patients. Future 
oncology (London, England) [Internet]. Future Oncol; 2015 [cited 2022 Jan 18];11:591-606. Available from: https://pubmed.ncbi.nlm.nih.gov/25686115/

23. Iyer KS, Newell JD, Jin D, Fuld MK, Saha PK, Hansdottir S, et al. Quantitative dual-energy computed tomography supports a vascular etiology of smoking-induced inflammatory lung disease. American Journal of Respiratory and Critical Care Medicine. 2016;193:652-61.

24. Reske A, Reske A, Gast H, Seiwerts M, Beda A, Gottschaldt U, et al. Extrapolation from ten sections can make CT-based quantification of lung aeration more practicable. Intensive Care Medicine. 2010;36:1836-44.

25. Ball L, Braune A, Corradi F, Brusasco C, Garlaschi A, Kiss T, et al. Ultra-low-dose sequential computed tomography for quantitative lung aeration assessment-a translational study. Intensive Care Medicine Experimental. 2017;5:19.

26. Rylander C, Högman M, Perchiazzi G, Magnusson a, Hedenstierna G. Oleic acid lung injury: a morphometric analysis using computed tomography. Acta anaesthesiologica Scandinavica [Internet]. 2004 [cited 2014 Sep 24];48:1123-9. Available from:

http://www.ncbi.nlm.nih.gov/pubmed/15352958

27. Pellegrini $M$, Larina A, Mourtos E, Frithiof R, Lipcsey $M$, Hultström $M$, et al. A quantitative analysis of extension and distribution of lung injury in COVID-19: a prospective study based on chest computed tomography. Critical care (London, England) [Internet]. Crit Care; 2021 [cited 2022 Jan 18];25:1-12. Available from: https://pubmed.ncbi.nlm.nih.gov/34348797/

28. McGoldrick E, Stewart F, Parker R, Dalziel SR. Antenatal corticosteroids for accelerating fetal lung maturation for women at risk of preterm birth. The Cochrane database of systematic reviews [Internet]. Cochrane Database Syst Rev; 2020 [cited 2022 Jan 18];12. Available from: https://pubmed.ncbi.nlm.nih.gov/33368142/

29. Murata T, Hori M, Sakamoto K, Karaki H, Ozaki H. Dexamethasone blocks hypoxia-induced endothelial dysfunction in organ-cultured pulmonary arteries. American Journal of Respiratory and Critical Care Medicine. 2004;170:647-55.

30. Villar J, Ferrando C, Martínez D, Ambrós A, Muñoz T, Soler JA, et al. Dexamethasone treatment for the acute respiratory distress syndrome: a multicentre, randomised controlled trial. The Lancet Respiratory Medicine. 2020;8:267-76.

31. Chaudhuri D, Sasaki K, Karkar A, Sharif S, Lewis K, Mammen MJ, et al. Corticosteroids in COVID-19 and non-COVID-19 ARDS: a systematic review and meta-analysis. Intensive Care Medicine. Springer Berlin Heidelberg; 2021;47:521-37.

32. Lipcsey M, Persson B, Eriksson O, Blom AM, Fromell K, Hultström M, et al. The Outcome of Critically III COVID-19 Patients Is Linked to Thromboinflammation Dominated by the Kallikrein/Kinin System. Frontiers in immunology [Internet]. Front Immunol; 2021 [cited 2022 Jan 18];12. Available from: https://pubmed.ncbi.nlm.nih.gov/33692801/

33. Sadeghipour P, Talasaz AH, Rashidi F, Sharif-Kashani B, Beigmohammadi MT, Farrokhpour M, et al. Effect of Intermediate-Dose vs Standard-Dose Prophylactic Anticoagulation on Thrombotic Events, 
Extracorporeal Membrane Oxygenation Treatment, or Mortality among Patients with COVID-19 Admitted to the Intensive Care Unit: The INSPIRATION Randomized Clinic. JAMA - Journal of the American Medical Association. 2021;325:1620-30.

34. Richter T, Bergmann R, Musch G, Pietzsch J, Koch T. Reduced pulmonary blood flow in regions of injury 2 hours after acid aspiration in rats. BMC Anesthesiology. BioMed Central Ltd.; 2015;15.

35. Dunham-Snary KJ, Wu D, Sykes EA, Thakrar A, Parlow LRG, Mewburn JD, et al. Hypoxic Pulmonary Vasoconstriction: From Molecular Mechanisms to Medicine. Chest. Elsevier Inc; 2017. p. 181-92.

36. Lang M, Som A, Carey D, Reid N, Mendoza DP, Flores EJ, et al. Pulmonary Vascular Manifestations of COVID-19 Pneumonia. Radiology: Cardiothoracic Imaging. Radiological Society of North America (RSNA); 2020;2:e200277.

37. Lang M, Som A, Mendoza DP, Flores EJ, Reid N, Carey D, et al. Hypoxaemia related to COVID-19: vascular and perfusion abnormalities on dual-energy CT. The Lancet Infectious Diseases. Lancet Publishing Group; 2020. p. 1365-6.

38. Wagner C, Griesel M, Mikolajewska A, Mueller A, Nothacker M, Kley K, et al. Systemic corticosteroids for the treatment of COVID-19. Cochrane Database of Systematic Reviews. 2021;2021.

39. Gierhardt M, Pak O, Walmrath D, Seeger W, Grimminger F, Ghofrani HA, et al. Impairment of hypoxic pulmonary vasoconstriction in acute respiratory distress syndrome. European respiratory review: an official journal of the European Respiratory Society [Internet]. Eur Respir Rev; 2021 [cited 2022 Feb 27];30. Available from: https://pubmed-ncbi-nlm-nih-gov.ezproxy.its.uu.se/34526314/

40. McGonagle D, Bridgewood C, Meaney JFM. A tricompartmental model of lung oxygenation disruption to explain pulmonary and systemic pathology in severe COVID-19. The Lancet Respiratory Medicine. Elsevier Ltd; 2021;9:665-72.

41. Mauri T, Spinelli E, Scotti E, Colussi G, Basile MC, Crotti S, et al. Potential for Lung Recruitment and Ventilation-Perfusion Mismatch in Patients with the Acute Respiratory Distress Syndrome from Coronavirus Disease 2019. Critical Care Medicine. 2020;48:1129-34.

42. Busana M, Giosa L, Cressoni M, Gasperetti A, Di Girolamo L, Martinelli A, et al. The impact of ventilation-perfusion inequality in COVID-19: A computational model. Journal of Applied Physiology. 2021;130:865-76.

43. Lu GM, Zhao Y, Zhang LJ, Schoepf UJ. Dual-energy CT of the lung. AJR American journal of roentgenology [Internet]. AJR Am J Roentgenol; 2012 [cited 2022 Jan 18];199. Available from: https://pubmed.ncbi.nlm.nih.gov/23097167/

44. Godoy MCB, Naidich DP, Marchiori E, Assadourian B, Leidecker C, Schmidt B, et al. Basic principles and postprocessing techniques of dual-energy $\mathrm{CT}$ : illustrated by selected congenital abnormalities of the thorax. Journal of thoracic imaging [Internet]. J Thorac Imaging; 2009 [cited 2022 Jan 18];24:152-9. Available from: https://pubmed.ncbi.nlm.nih.gov/19465844/

45. Lang M, Som A, Carey D, Reid N, Mendoza DP, Flores EJ, et al. Pulmonary Vascular Manifestations of COVID-19 Pneumonia. Radiology Cardiothoracic imaging [Internet]. Radiol Cardiothorac Imaging; 2020 [cited 2022 Jan 18];2. Available from: https://pubmed.ncbi.nIm.nih.gov/34036264/ 
46. Ameli-Renani S, Rahman F, Nair A, Ramsay L, Bacon JL, Weller A, et al. Dual-energy CT for imaging of pulmonary hypertension: Challenges and opportunities. Radiographics. Radiological Society of North America Inc.; 2014;34:1769-90.

\section{Tables}

Table 1. Descriptive statistics for all patients included in the study (sample size $=60$ ). Data were reported as median values $\left(25^{\text {th }}-75^{\text {th }}\right.$ percentile) or numerosity (\%). BMI: body mass index, SAPS 3 : the simplified acute physiology score $3, \mathrm{~F}_{1} \mathrm{O}_{2}$ : inspiratory fraction of oxygen, $\mathrm{PaO}_{2}$ : partial pressure of arterial oxygen, $\mathrm{SpO}_{2}$ : peripheral oxygen saturation, $\mathrm{PCO}_{2}$ : partial pressure of arterial carbon dioxide. Days of invasive ventilation, ventilatory settings and respiratory mechanics values refer only to the subgroup of mechanically ventilated patients. Spontaneously breathing patients refers to patients with preserved respiratory drive both with and without invasive mechanical ventilation. 


\begin{tabular}{|c|c|c|c|}
\hline & Median & $25^{\text {th }}$ & $75^{\text {th }}$ \\
\hline Age (years) & 63 & 57 & 68 \\
\hline BMI & 31 & 26 & 34 \\
\hline \multirow[t]{2}{*}{ Female } & $\mathrm{n}$ & $\%$ & \\
\hline & 12 & 20 & \\
\hline Clinical history before ICU stay & $\mathrm{n}$ & $\%$ & \\
\hline Previous pulmonary disease & 16 & 27 & \\
\hline Thrombotic events before ICU & 6 & 10 & \\
\hline At ICU admission & Median & $25^{\text {th }}$ & $75^{\text {th }}$ \\
\hline Respiratory rate (bpm) & 26 & 23 & 33 \\
\hline SAPS 3 & 50 & 46 & 59 \\
\hline Days of COVID-19 symptoms & 10 & 9 & 12 \\
\hline $\mathrm{F}_{1} \mathrm{O}_{2}$ & 60 & 50 & 70 \\
\hline $\mathrm{pH}$ & 7.47 & 7.44 & 7.48 \\
\hline $\mathrm{PaCO}_{2}[\mathrm{~mm} \mathrm{Hg}]$ & 35 & 32 & 37 \\
\hline $\mathrm{PaO}_{2} / \mathrm{F}_{1} \mathrm{O}_{2}$ ratio $[\mathrm{mm} \mathrm{Hg}]$ & 117 & 96 & 140 \\
\hline $\mathrm{SpO}_{2}[\%]$ & 94 & 93 & 95 \\
\hline Weight [kg] & 98 & 82 & 109 \\
\hline \multirow[t]{2}{*}{ Deltaparin [IE] / kg } & 140 & 116 & 158 \\
\hline & $\mathrm{n}$ & $\%$ & \\
\hline Intubated patients & 21 & 35 & \\
\hline
\end{tabular}

\begin{tabular}{llll}
\hline On DECT day & Median & $25^{\text {th }}$ & $75^{\text {th }}$ \\
\hline Days of invasive ventilation & 6 & 1 & 12 \\
\hline PEEP $\left[\mathrm{cm} \mathrm{H} \mathrm{H}_{2} \mathrm{O}\right]$ & 12 & 6 & 14 \\
\hline Static compliance & 40 & 30 & 61 \\
\hline
\end{tabular}




\begin{tabular}{|c|c|c|c|}
\hline Tidal volume $[\mathrm{mL}] / \mathrm{kg}$ PBW & 7 & 6 & 10 \\
\hline $\mathrm{pH}$ & 7.44 & 7.38 & 7.47 \\
\hline $\mathrm{PaCO}_{2}[\mathrm{~mm} \mathrm{Hg}]$ & 39 & 35 & 49 \\
\hline $\mathrm{PaO}_{2} / \mathrm{FIO}_{2}$ ratio $[\mathrm{mm} \mathrm{Hg}]$ & 126 & 110 & 150 \\
\hline $\mathrm{SpO}_{2}[\%]$ & 94 & 93 & 95 \\
\hline Weight (kg) & 96 & 82 & 106 \\
\hline Ferritin $[\mu \mathrm{g} / \mathrm{l}]$ & 1948 & 876 & 2628 \\
\hline D-dimer [ng/ml] & 2 & 1 & 4 \\
\hline Interleukin-6 (IL-6) [pg/ml] & 169 & 73 & 236 \\
\hline \multirow[t]{2}{*}{ Factor Xa [KIE/I] } & 0.53 & 0.43 & 0.67 \\
\hline & $\mathrm{n}$ & $\%$ & \\
\hline Intubated patients & 24 & 41 & \\
\hline Spontaneously breathing patients & 36 & 64 & \\
\hline Acute trombotic events before DECT & 13 & 22 & \\
\hline At ICU discharge & Median & $25^{\text {th }}$ & $75^{\text {th }}$ \\
\hline Days of invasive ventilation & 10 & 7 & 23 \\
\hline Days of ICU stay & 10 & 6 & 17 \\
\hline Highest Ferritin $[\mu \mathrm{g} / \mathrm{l}]$ & 1836 & 949 & 3425 \\
\hline Highest D-dimer [ng/ml] & 3 & 1 & 8 \\
\hline \multirow[t]{2}{*}{ Highest Interleukin-6 (IL-6) [pg/ml] } & 113 & 67 & 205 \\
\hline & $\mathrm{n}$ & $\%$ & \\
\hline Alive 30 days after ICU & 43 & 71 & \\
\hline Invasive mechancial ventilation & 32 & 53 & \\
\hline Thrombotic events & 16 & 27 & \\
\hline
\end{tabular}

Table 2. Descriptive statistics for the two patients' subgroups: No-Steroids group (left, simple size $=17$ ) and Steroids group (right, simple size $=43$ ). Data were reported as median values $\left(25^{\text {th }}-75^{\text {th }}\right.$ percentile) or numerosity (\%). The analyzed variables are the same as in Table 1. Wilcoxon rank sum test to detect 


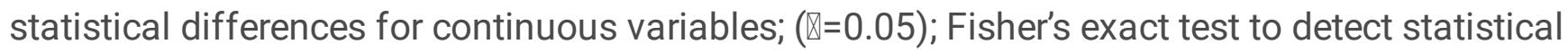
differences for categorical variables; $(\mathbb{V}=0.05)$; *: to mark statistically significant differences. 
$\begin{array}{lll}\begin{array}{l}\text { No-Steroids } \\ \text { size }=17)\end{array} & \text { (sample } & \begin{array}{l}\text { Steroids } \\ \text { (sample size }= \\ 43)\end{array}\end{array}$

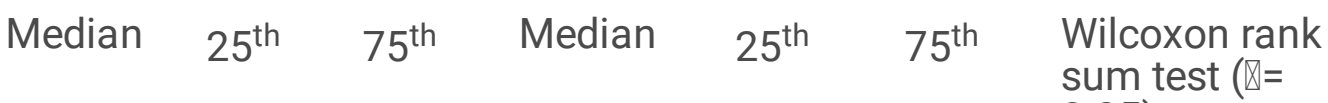

0.05 )

$\begin{array}{llllllll}\text { Age (years) } & 62 & 55 & 68 & 64 & 58 & 68 & 0.37 \\ \text { BMI } & 29 & 27 & 33 & 31 & 26 & 36 & 1\end{array}$

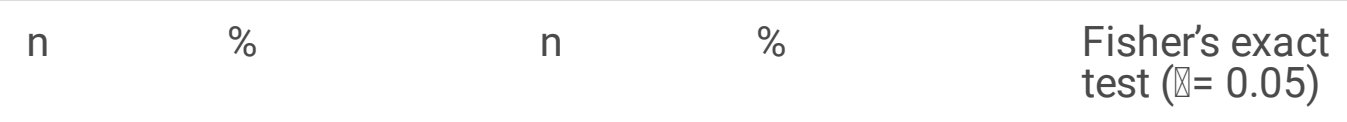

Female

16

11

26

0.15

\begin{tabular}{lccccc}
$\begin{array}{l}\text { Clinical history before } \\
\text { ICU stay }\end{array}$ & $\mathrm{n}$ & $\%$ & $\mathrm{n}$ & $\%$ & \\
\hline $\begin{array}{l}\text { Previous pulmonary } \\
\text { disease }\end{array}$ & 5 & 29 & 11 & 26 & 0.76 \\
$\begin{array}{l}\text { Thrombotic events } \\
\text { before ICU }\end{array}$ & 2 & 7 & 4 & 9 & 1 \\
\hline
\end{tabular}

\begin{tabular}{|c|c|c|c|c|c|c|c|}
\hline At ICU admission & Median & $25^{\mathrm{th}}$ & $75^{t}$ & Median & $25^{\text {th }}$ & $75^{\text {th }}$ & 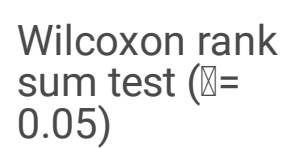 \\
\hline
\end{tabular}

\begin{tabular}{|c|c|c|c|c|c|c|c|}
\hline Respiratory rate (bpm) & 25 & 22 & 34 & 26 & 24 & 32 & 0.72 \\
\hline SAPS 3 & 49 & 46 & 59 & 50 & 45 & 58 & 0.97 \\
\hline $\begin{array}{l}\text { Days of COVID-19 } \\
\text { symptoms }\end{array}$ & 10 & 10 & 12 & 11 & 9 & 12 & 0.84 \\
\hline $\mathrm{F}_{1} \mathrm{O}_{2}$ & 60 & 50 & 70 & 60 & 55 & 70 & 0.54 \\
\hline $\mathrm{pH}$ & 7.45 & 7.43 & 7.48 & 7.47 & 7.45 & 7.48 & 0.56 \\
\hline $\mathrm{PaCO}_{2}[\mathrm{~mm} \mathrm{Hg}]$ & 37 & 32 & 41 & 35 & 32 & 37 & 0.22 \\
\hline $\begin{array}{l}\mathrm{PaO}_{2} / \mathrm{F}_{1} \mathrm{O}_{2} \text { ratio }[\mathrm{mm} \\
\mathrm{Hg}]\end{array}$ & 113 & 95 & 149 & 120 & 109 & 138 & 0.88 \\
\hline $\mathrm{SpO}_{2}[\%]$ & 94 & 92 & 95 & 94 & 93 & 95 & 0.42 \\
\hline Weight [kg] & 99 & 87 & 107 & 98 & 81 & 109 & 0.49 \\
\hline Deltaparin [IE] / kg & 114 & 106 & 146 & 144 & 125 & 162 & 0.11 \\
\hline
\end{tabular}




\begin{tabular}{|c|c|c|c|c|c|c|c|}
\hline & $\mathrm{n}$ & $\%$ & & $\mathrm{n}$ & $\%$ & & 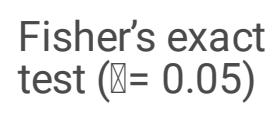 \\
\hline Intubated patients & 5 & 29 & & 16 & 37 & & 0.77 \\
\hline On DECT day & Median & $25^{\text {th }}$ & $75^{\text {th }}$ & Median & $25^{\text {th }}$ & $75^{\text {th }}$ & 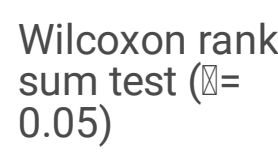 \\
\hline $\begin{array}{l}\text { Days of invasive } \\
\text { ventilation }\end{array}$ & 8 & 6 & 13 & 2 & 1 & 9 & 0.31 \\
\hline PEEP [cm $\left.\mathrm{H}_{2} \mathrm{O}\right]$ & 14 & 12 & 15 & 10 & 6 & 12 & 0.08 \\
\hline Static compliance & 38 & 23 & 60 & 43 & 35 & 60 & 0.49 \\
\hline $\begin{array}{l}\text { Tidal volume }[\mathrm{mL}] / \mathrm{kg} \\
\text { PBW }\end{array}$ & 7 & 6 & 9 & 7 & 6 & 10 & 0.37 \\
\hline $\mathrm{pH}$ & 7.44 & 7.38 & 7.49 & 7.43 & 7.38 & 7.46 & 0.45 \\
\hline $\mathrm{PaCO}_{2}[\mathrm{~mm} \mathrm{Hg}]$ & 41 & 32 & 45 & 38 & 36 & 49 & 0.95 \\
\hline $\begin{array}{l}\mathrm{PaO}_{2} / \mathrm{FIO}_{2} \text { ratio }[\mathrm{mm} \\
\mathrm{Hg}]\end{array}$ & 125 & 111 & 137 & 134 & 111 & 153 & 0.43 \\
\hline $\mathrm{SpO}_{2}[\%]$ & 94 & 93 & 95 & 94 & 92 & 95 & 0.86 \\
\hline Weight (kg) & 95 & 84 & 111 & 96 & 80 & 104 & 0.43 \\
\hline Ferritin $[\mu \mathrm{g} / \mathrm{l}]$ & 2204 & 1075 & 2947 & 1807 & 1009 & 2162 & 0.27 \\
\hline D-dimer [ng/ml] & 4 & 1 & 15 & 2 & 1 & 4 & 0.72 \\
\hline $\begin{array}{l}\text { Interleukin-6 (IL-6) } \\
\text { [pg/ml] }\end{array}$ & 173 & 108 & 246 & 50 & 39 & 204 & 0.21 \\
\hline \multirow[t]{2}{*}{ Factor Xa [KIE/I] } & 0.51 & 0.45 & 0.6 & 0.59 & 0.43 & 0.67 & 0.18 \\
\hline & $\mathrm{n}$ & $\%$ & & $\mathrm{n}$ & $\%$ & & 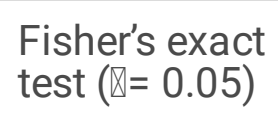 \\
\hline Intubated patients & 8 & 47 & & 16 & 37 & & 0.77 \\
\hline $\begin{array}{l}\text { Spontaneously } \\
\text { breathing patients }\end{array}$ & 9 & 52 & & 27 & 69 & & 1 \\
\hline $\begin{array}{l}\text { Acute trombotic events } \\
\text { before } D E C T\end{array}$ & 7 & 41 & & 6 & 14 & & $0.03^{*}$ \\
\hline
\end{tabular}




\begin{tabular}{|c|c|c|c|c|c|c|c|}
\hline At ICU discharge & Median & $25^{\text {th }}$ & $75^{\text {th }}$ & Median & $25^{\text {th }}$ & $75^{\text {th }}$ & 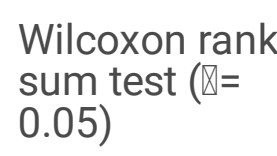 \\
\hline $\begin{array}{l}\text { Days of invasive } \\
\text { ventilation }\end{array}$ & 12 & 9 & 23 & 8 & 5 & 21 & 0.14 \\
\hline Days of ICU stay & 16 & 6 & 25 & 8 & 6 & 16 & 0.45 \\
\hline Highest Ferritin $[\mu \mathrm{g} / \mathrm{l}]$ & 3441 & 1981 & 6795 & 1406 & 619 & 2553 & $0.03^{\star}$ \\
\hline $\begin{array}{l}\text { Highest D-dimer } \\
\text { [ng/ml] }\end{array}$ & 3 & 1 & 22 & 3 & 1 & 8 & 0.9 \\
\hline $\begin{array}{l}\text { Highest Interleukin-6 } \\
(\mathrm{IL}-6)[\mathrm{pg} / \mathrm{ml}]\end{array}$ & 226 & 130 & 247 & 86 & 37 & 144 & $0.01 *$ \\
\hline
\end{tabular}

\begin{tabular}{|c|c|c|c|c|c|}
\hline & $\mathrm{n}$ & $\%$ & $\mathrm{n}$ & $\%$ & $\begin{array}{l}\text { Fisher's exact } \\
\text { test }(\nabla=0.05)\end{array}$ \\
\hline Alive 30 days after ICU & 12 & 71 & 31 & 72 & 0.49 \\
\hline $\begin{array}{l}\text { Invasive mechancial } \\
\text { ventilation }\end{array}$ & 10 & 59 & 22 & 51 & 0.77 \\
\hline Thrombotic events & 8 & 47 & 8 & 19 & $0.04^{\star}$ \\
\hline
\end{tabular}

Table 3. Lung volume ( $\mathrm{ml}$ ) calculated for the whole lung parenchyma as well as for each HU compartment (hyper-, normally, poorly and non-inflated). Panel A: whole study population $(n=60)$; Panel B: No-Steroids group ( $n=17)$; Panel C: Steroids group $(n=43)$. Each HU compartment was reported as absolute values as well as percentage of the total lung parenchyma. Data are reported as median values and interquartile ranges $\left(25^{\text {th }}-75^{\text {th }}\right.$ percentiles). Wilcoxon rank sum test was used to detect statistical

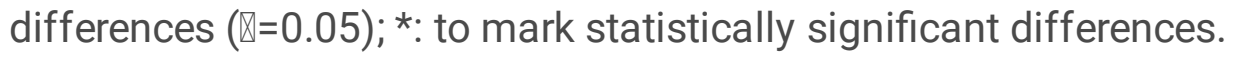




\section{Panel A}

\section{ALL PATIENTS}

\begin{tabular}{llllllll} 
& \multicolumn{3}{l}{ Lung Volume $(\mathrm{ml})$} & \multicolumn{2}{l}{ Lung Volume $(\%)$} \\
& Median & $25^{\text {th }}$ & $75^{\text {th }}$ & Median & $25^{\text {th }}$ & $75^{\text {th }}$ \\
\hline Total lung & 2175 & 1477 & 2799 & & & \\
\hline Hyperinflated & 523 & 201 & 926 & 24 & 13 & 37 \\
\hline Normally inflated & 698 & 532 & 1042 & 36 & 28 & 43 \\
\hline Poorly inflated & 503 & 376 & 651 & 26 & 19 & 32 \\
\hline Non inflated & 174 & 79 & 282 & 9 & 3 & 14
\end{tabular}

\section{Panel B}

No-Steroids

\begin{tabular}{llllllll} 
& \multicolumn{2}{l}{ Lung Volume $(\mathrm{ml})$} & \multicolumn{3}{l}{ Lung Volume (\%) } \\
& Median & $25^{\text {th }}$ & $75^{\text {th }}$ & Median & $25^{\text {th }}$ & $75^{\text {th }}$ \\
\hline Total lung & 2223 & 1718 & 2841 & & & \\
Hyperinflated & 609 & 406 & 916 & 25 & 21 & 32 \\
\hline Normally inflated & 675 & 533 & 1117 & 36 & 30 & 40 \\
\hline Poorly inflated & 515 & 376 & 643 & 25 & 20 & 28 \\
\hline Non inflated & 270 & 188 & 296 & 10 & 9 & 17
\end{tabular}

\section{Panel C}

Steroids

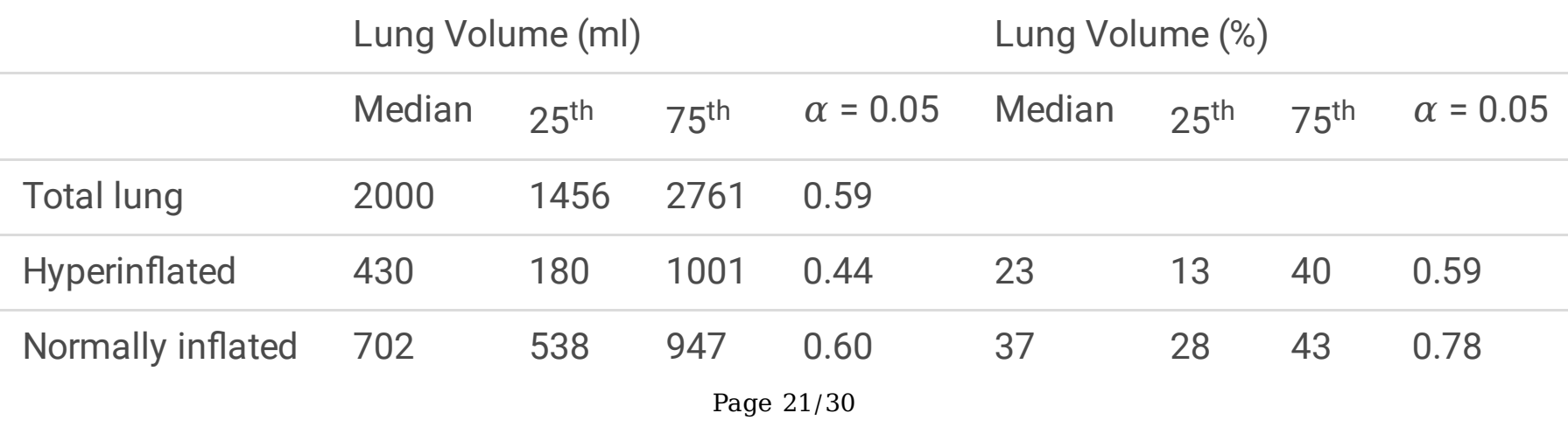




\begin{tabular}{lcccccccc}
\hline Poorly inflated & 491 & 377 & 654 & 0.67 & 26 & 16 & 35 & 0.45 \\
\hline Non inflated & 127 & 66 & 196 & $0.01^{*}$ & 7 & 2 & 12 & $0.02^{*}$
\end{tabular}

Table 4. Gas volume (ml) calculated for the whole lung parenchyma as well as for each HU compartment (hyper-, normally, poorly and non-inflated). Panel A: whole study population $(n=60) ;$ Panel B: No-Steroids group ( $n=17)$; Panel C: Steroids group $(n=43)$. Each HU compartment was reported as absolute values as well as percentage of the total lung parenchyma. Data are reported as median values and interquartile ranges $\left(25^{\text {th }}-75^{\text {th }}\right.$ percentiles $)$. Wilcoxon rank sum test was used to detect statistical differences $(\nabla=0.05)$; *: to mark statistically significant differences. 


\section{Panel A}

\section{ALL PATIENTS}

\begin{tabular}{llllllll} 
& \multicolumn{2}{l}{ Gas Volume $(\mathrm{ml})$} & \multicolumn{3}{l}{ Gas Volume $(\%)$} \\
& Median & $25^{\text {th }}$ & $75^{\text {th }}$ & Median & $25^{\text {th }}$ & $75^{\text {th }}$ \\
\hline Total lung & 1275 & 753 & 1728 & & & \\
\hline Hyperinflated & 483 & 196 & 852 & 36 & 24 & 50 \\
\hline Normally inflated & 492 & 384 & 748 & 48 & 39 & 56 \\
\hline Poorly inflated & 176 & 144 & 257 & 17 & 11 & 25 \\
\hline Non inflated & 37 & 25 & 43 & 3 & 2 & 4
\end{tabular}

\section{Panel B}

No-Steroids

\begin{tabular}{|llllllll} 
& \multicolumn{3}{l}{ Gas Volume $(\mathrm{ml})$} & \multicolumn{3}{l}{ Gas Volume $(\%)$} \\
& Median & $25^{\text {th }}$ & $75^{\text {th }}$ & Median & $25^{\text {th }}$ & $75^{\text {th }}$ \\
\hline Total lung & 1275 & 989 & 1755 & & & \\
\hline Hyperinflated & 541 & 370 & 849 & 40 & 33 & 49 \\
\hline Normally inflated & 494 & 384 & 780 & 46 & 39 & 54 \\
\hline Poorly inflated & 180 & 136 & 231 & 16 & 13 & 18 \\
\hline Non inflated & 33 & 26 & 42 & 3 & 2 & 3
\end{tabular}

\section{Panel C}

\section{Steroids}

\begin{tabular}{lccccccccc} 
& \multicolumn{3}{l}{ Gas Volume $(\mathrm{ml})$} & \multicolumn{9}{l}{ Gas Volume (\%) } \\
& Median & $25^{\text {th }}$ & $75^{\text {th }}$ & $\alpha=0.05$ & Median & $25^{\text {th }}$ & $75^{\text {th }}$ & $\alpha=0.05$ \\
\hline Total lung & 1275 & 743 & 1683 & 0.71 & & & & \\
Hyperinflated & 412 & 177 & 887 & 0.48 & 36 & 24 & 53 & 0.49 \\
\hline Normally inflated & 491 & 388 & $\begin{array}{c}662 \\
\text { Page 23/30 }\end{array}$ & 0.62 & 49 & 39 & 56 & 0.66
\end{tabular}




\begin{tabular}{lllllllll}
\hline Poorly inflated & 174 & 147 & 260 & 0.88 & 18 & 10 & 27 & 0.39 \\
\hline Non inflated & 38 & 25 & 44 & 0.74 & 3 & 2 & 4 & 0.37
\end{tabular}

Table 5. Lung weight ( $\mathrm{g}$ ) calculated for the whole lung parenchyma as well as for each HU compartment (hyper-, normally, poorly and non-inflated). Panel A: whole study population $(n=60) ;$ Panel B: No-Steroids group ( $n=17)$; Panel C: Steroids group $(n=43)$. Each HU compartment was reported as absolute values as well as percentage of the total lung parenchyma. Data are reported as median values and interquartile ranges $\left(25^{\text {th }}-75^{\text {th }}\right.$ percentiles $)$. Wilcoxon rank sum test was used to detect statistical differences $(\nabla=0.05)$; *: to mark statistically significant differences. 


\section{Panel A}

\section{ALL PATIENTS}

\begin{tabular}{llllllll}
\hline & \multicolumn{3}{l}{ Weight (g) } & \multicolumn{2}{l}{ Weight (\%) } \\
& Median & $25^{\text {th }}$ & $75^{\text {th }}$ & Median & $25^{\text {th }}$ & $75^{\text {th }}$ \\
\hline Total lung & 911 & 706 & 1125 & & & \\
\hline Hyperinflated & 107 & 54 & 162 & 11 & 6 & 17 \\
\hline Normally inflated & 259 & 193 & 396 & 31 & 23 & 38 \\
\hline Poorly inflated & 383 & 282 & 477 & 40 & 31 & 48 \\
\hline Non inflated & 198 & 114 & 313 & 22 & 13 & 30
\end{tabular}

\section{Panel B}

No-Steroids

\begin{tabular}{llllllll} 
& \multicolumn{5}{l}{ Weight $(\mathrm{g})$} & \multicolumn{2}{l}{ Weight (\%) } \\
& Median & $25^{\text {th }}$ & $75^{\text {th }}$ & Median & $25^{\text {th }}$ & $75^{\text {th }}$ \\
\hline Total lung & 1005 & 868 & 1349 & & & \\
\hline Hyperinflated & 118 & 91 & 160 & 12 & 8 & 13 \\
\hline Normally inflated & 246 & 192 & 405 & 29 & 22 & 36 \\
\hline Poorly inflated & 397 & 286 & 506 & 39 & 34 & 44 \\
\hline Non inflated & 282 & 219 & 332 & 26 & 22 & 31
\end{tabular}

\section{Panel C}

\section{Steroids}

\begin{tabular}{|c|c|c|c|c|c|c|c|c|}
\hline & \multicolumn{4}{|c|}{ Weight (g) } & \multicolumn{4}{|c|}{ Weight (\%) } \\
\hline & Median & $25^{\text {th }}$ & $75^{\text {th }}$ & $\alpha=0.05$ & Median & $25^{\text {th }}$ & $75^{\text {th }}$ & $\alpha=0.05$ \\
\hline Total lung & 853 & 696 & 1005 & 0.01 & & & & \\
\hline Hyperinflated & 94 & 52 & 172 & 0.57 & 11 & 6 & 19 & 0.93 \\
\hline Normally inflated & 261 & 194 & 366 & 0.85 & 31 & 26 & 39 & 0.34 \\
\hline
\end{tabular}




\begin{tabular}{lllllllll}
\hline Poorly inflated & 378 & 279 & 464 & 0.60 & 42 & 31 & 51 & 0.44 \\
\hline Non inflated & 157 & 100 & 214 & $0.01^{\star}$ & 18 & 12 & 28 & $0.03^{*}$
\end{tabular}

\section{Figures}
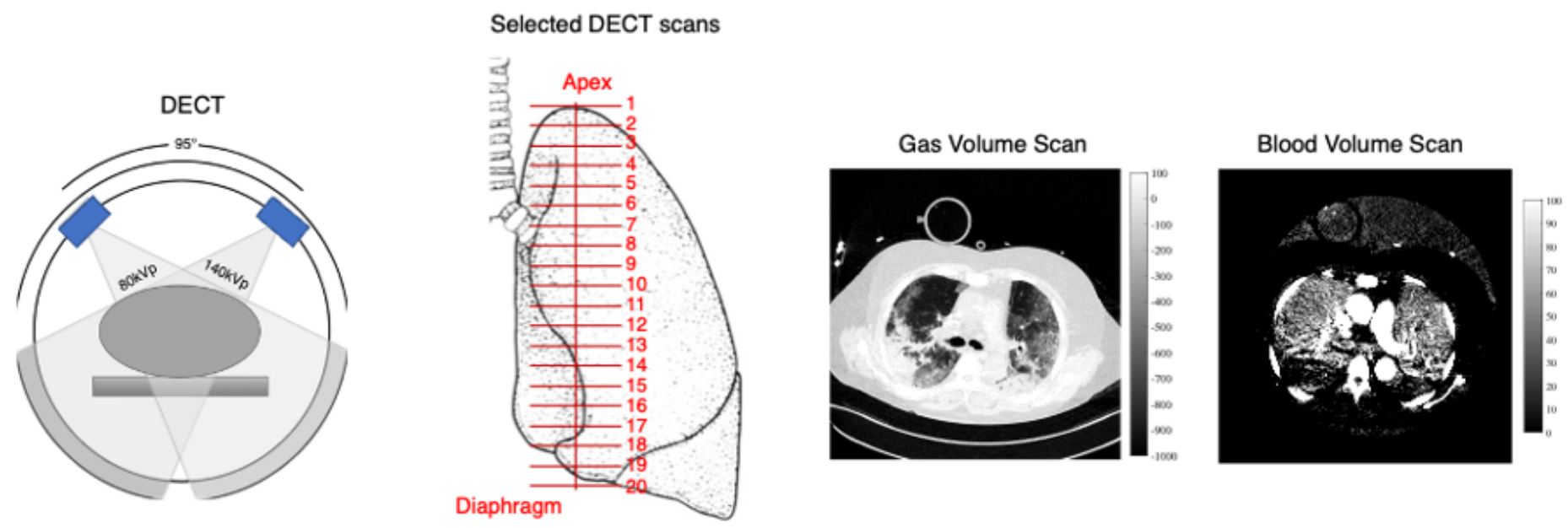

Figure 1

\section{Figure 1}

Dual energy computed tomography (DECT) image acquisition and analysis. Left panel. The DECT technique used. Central panel. Coronal representation of a lung. Twenty DECT-images, equally distributed between the apex and the diaphragmatic dome, were selected along the cranial-caudal axis. Both lungs were analysed. Right panel. Representative example of virtual unenhanced non-contrast (VNC) images corresponding to a gas-distribution (inflation) map and virtual unenhanced contrast (VC) images corresponding to a blood-distribution (perfusion) map. 

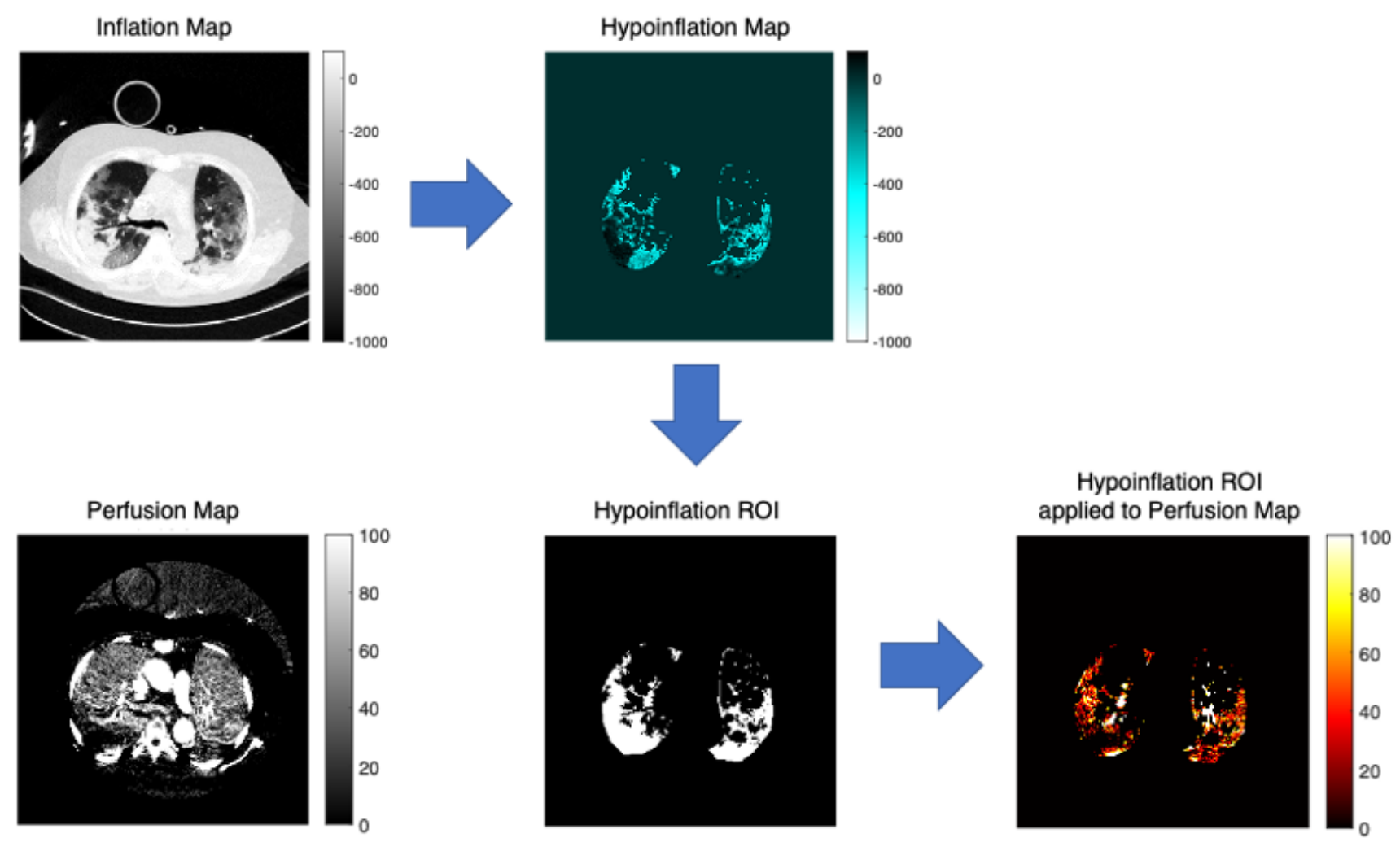

Figure 2

Figure 2

Dual energy computed tomography image analysis. Inflation maps were characterized by a HU range between $-1,000$ and $+100 \mathrm{HU}$. Perfusion maps were characterized by a $\mathrm{HU}$ range between -100 and $+150 \mathrm{HU}$. To assess hypoxic pulmonary vasoconstriction, perfusion distribution was assessed for the whole lung and for the hypoinflated lung, the latter characterized by poorly inflated and not inflated lung regions (HU between -500 and +100 ). A region of interest for hypoinflated lung (Hypoinflation ROI) was obtained extrapolating hypoinflated areas (Hypoinflation Map) from the Inflation Map. Hence, the hypoinflated ROI was applied to Perfusion Map to analyze perfusion distribution of the hypoinflated areas. 


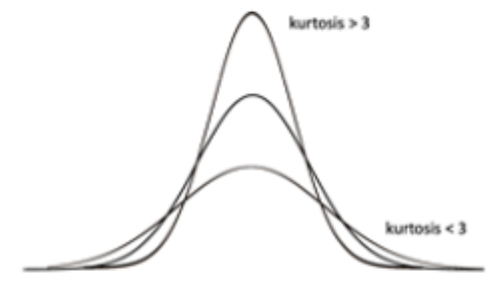

Panel A
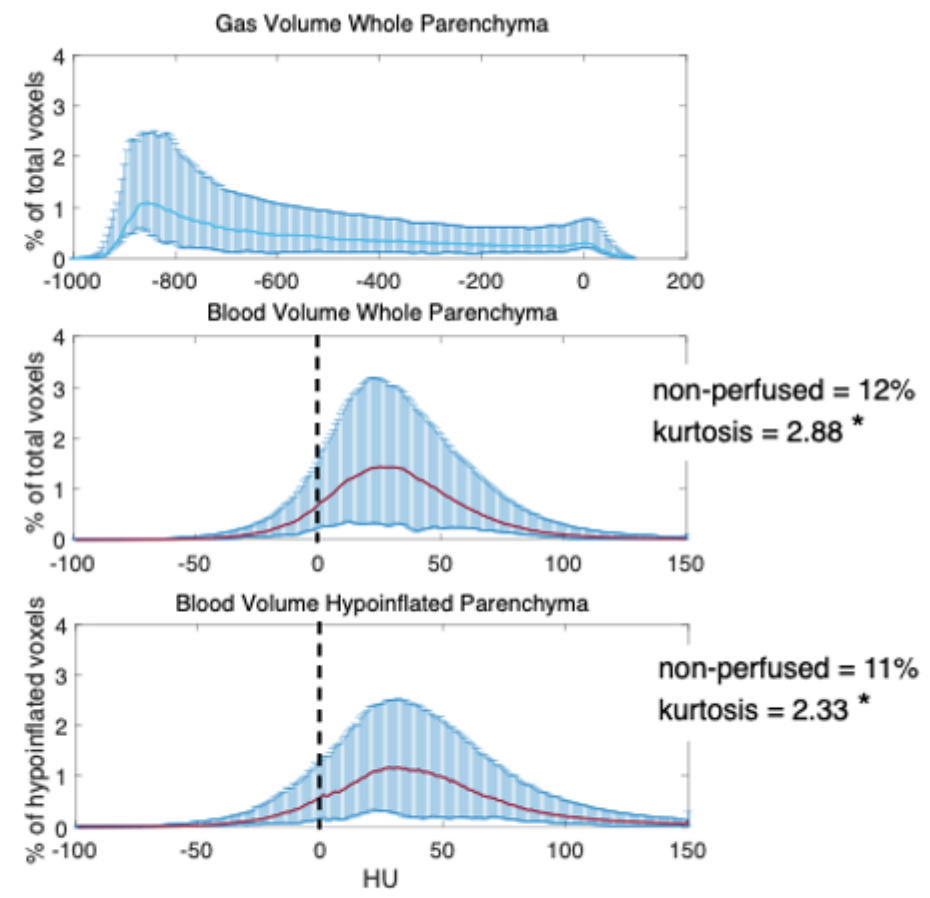

Panel B

Figure 3

\section{Figure 3}

HU distribution for gas volume (inflation) map and blood volume (perfusion) maps, for the whole study population ( $n=60$ patients). Panel $A$. an explanatory figure defining the kurtosis used to define homogeneity of perfusion. A high kurtosis indicates high homogeneity and reduced hypoxic pulmonary vasoconstriction. Panel B. Above: the HU distribution for inflation maps in the whole lung parenchyma; middle: HU distribution for perfusion maps in the whole lung parenchyma; below: HU distribution for perfusion maps in the hypoinflated lung parenchyma. $x$-axis: HU values. $y$-axis: percent of voxels compared to the total amount of voxels. Values represented as median $\left(25^{\text {th }}\right.$ and $75^{\text {th }}$ percentiles $)$ or percent. 
No-Steroids Group $(\mathrm{n}=17$ )
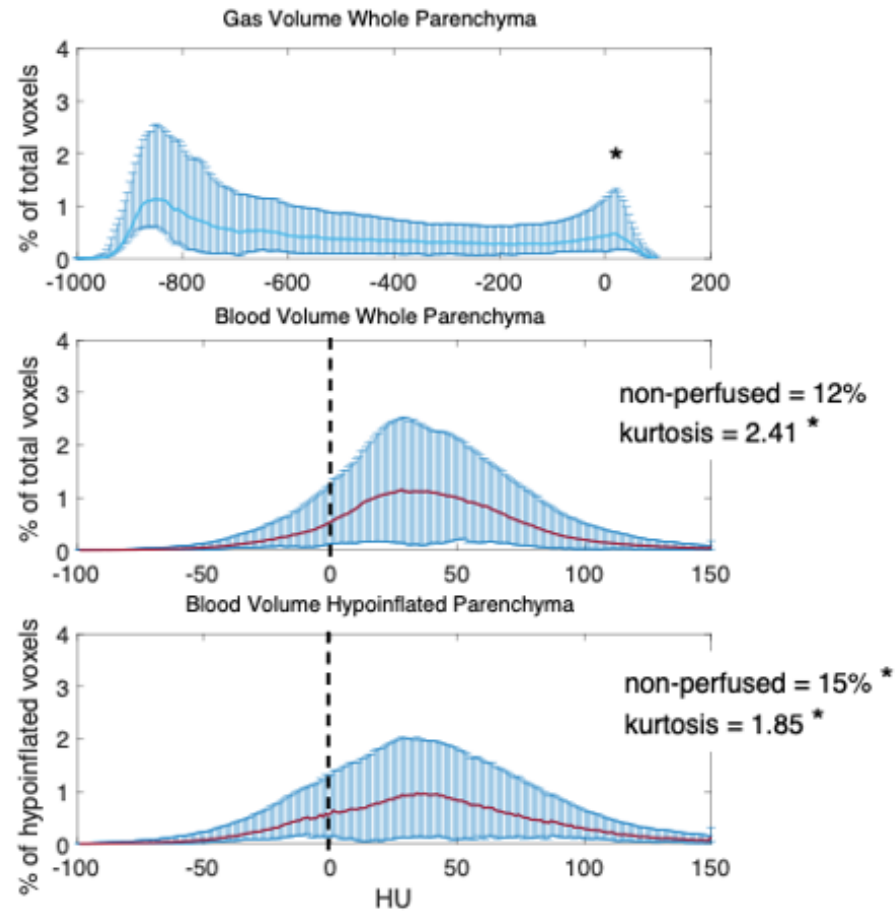

Steroids Group $(n=43)$
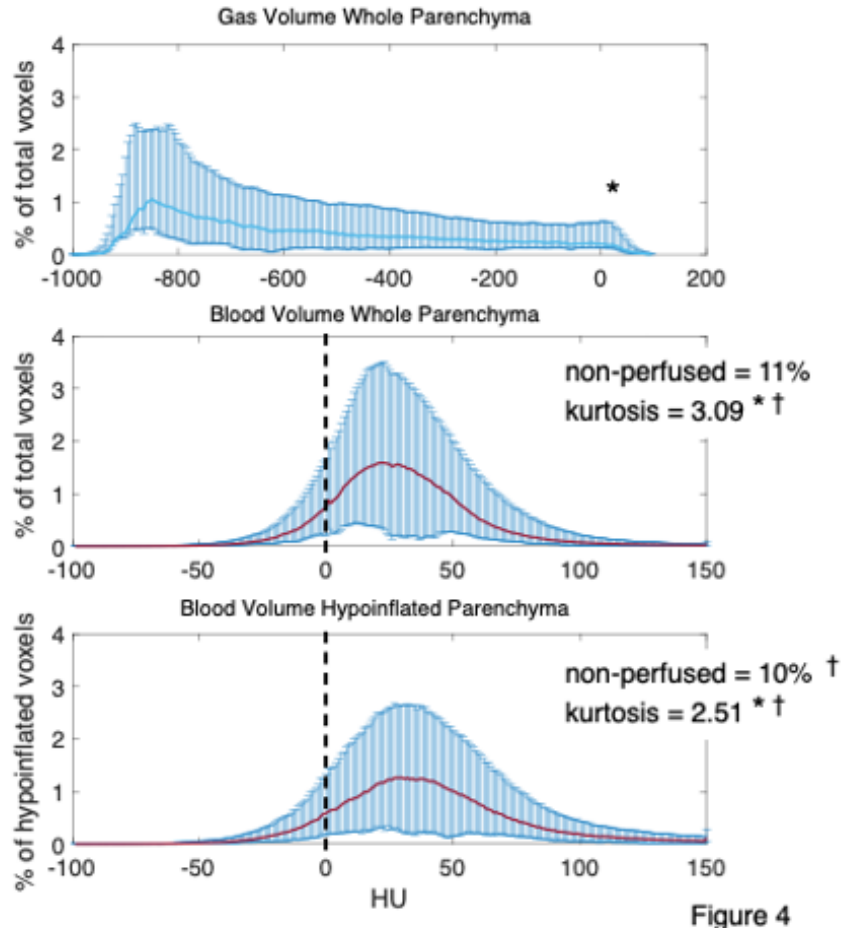

Figure 4

HU distribution for gas volume (inflation) map and blood volume (perfusion) maps, separately for the NoSteroids group ( $n=17$ patients; Panel A) and the Steroids group ( $n=43$ patients; Panel B). Above: the HU distribution for inflation maps in the whole lung parenchyma; middle: HU distribution for perfusion maps in the whole lung parenchyma; below: HU distribution for perfusion maps in the hypoinflated lung parenchyma. x-axis: HU values. $y$-axis: percent of voxels compared to the total amount of voxels. Values represented as median $\left(25^{\text {th }}\right.$ and $75^{\text {th }}$ percentiles) or percent. *: for statistical differences between Whole lung parenchyma (middle) and Hypoinflated parenchyma (Below); †: for statistical differences between the No-Steroids group (Panel A) and the Steroids group (Panel B). 
No-Steroids Group
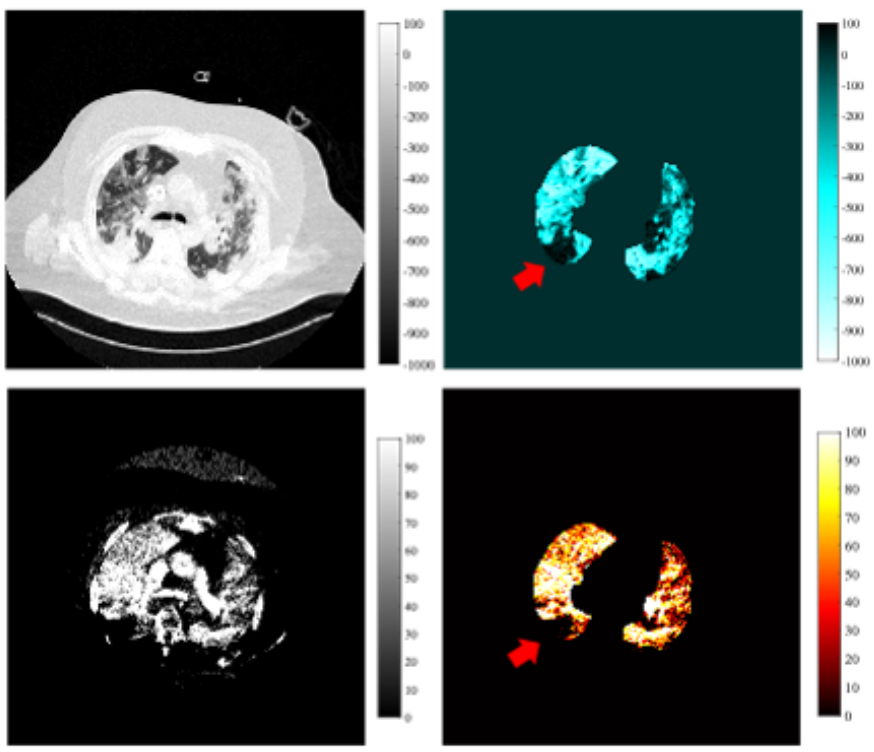

Patient 43. 14 days from onset of symptoms, 7 days of mechanical ventilation before CT, level 12 of 20 .
Steroids Group
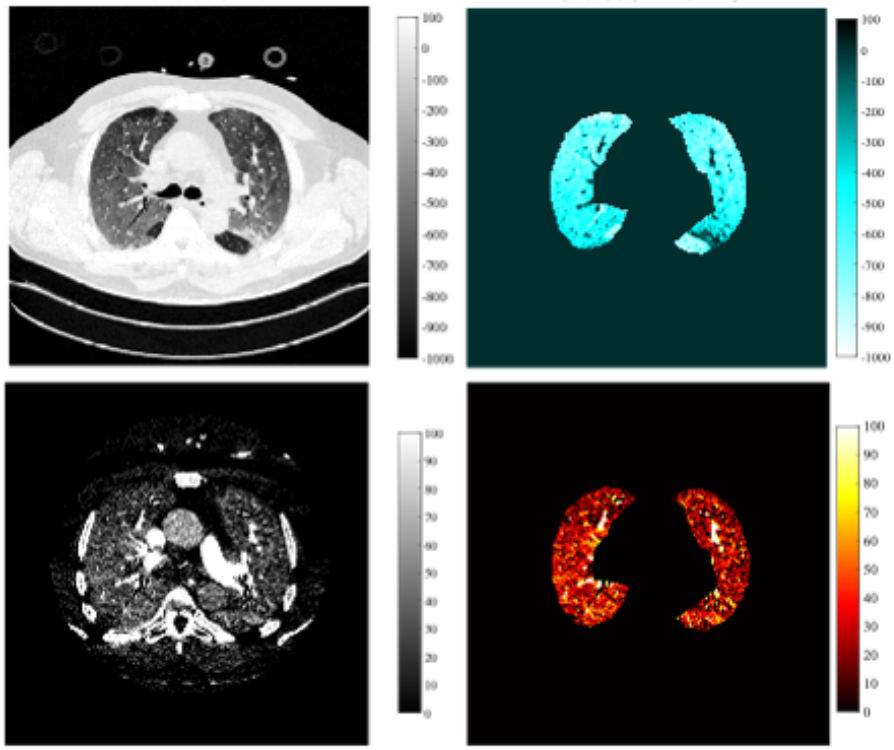

Patient 37. 7 days from onset of symptoms, 1 day of mechanical ventilation before CT, level 11 of 20 .

Figure 5

\section{Figure 5}

Representative example of DECT scans collected on the No-Steroids Group (left) and the Steroids Group (right). On the left: Patient not treated with steroids (No-Steroids group). On the right: Patient treated with steroids (Steroids group). For both No-Steroids and Steroids group, upper images show a virtual unenhanced non-contrast image (left) and the corresponding inflation map (right); lower images show a virtual unenhanced image (left) and the corresponding perfusion map (right). Different colormap have been used to emphasize different degree of inflation and perfusion. For inflation maps the range of $\mathrm{HU}$ is between -1000 and $+100 \mathrm{HU}$. For perfusion maps the range of $\mathrm{HU}$ is between 0 and $+100 \mathrm{HU}$. $0 \mathrm{HU}$ corresponding to non-perfused areas, $100 \mathrm{HU}$ corresponding to highly perfused areas. The red arrow to indicate areas of preserved hypoxic pulmonary vasoconstriction where areas of low perfusion correspond to areas of low inflation.

\section{Supplementary Files}

This is a list of supplementary files associated with this preprint. Click to download.

- Supplementarymaterial.docx 